\title{
Development and validation of a multidimensional questionnaire for evaluating quality of life in melasma (HRQ-melasma) ${ }^{*}$
}

\author{
Camila Fernandes Pollo ${ }^{1}$ \\ Silmara Meneguin ${ }^{1}$
}

\author{
Luciane Donida Bartoli Miot ${ }^{2}$ \\ Hélio Amante Miot $^{2}$
}

DOI: http:/ / dx.doi.org/10.1590/abd1806-4841.20186780

\begin{abstract}
BACKGROUND: Melasma has a major impact on quality of life. MELASQoL is the only validated specific psychometric instrument to evaluate melasma QoL.

Овјестіvе: To develop and validate a multidimensional questionnaire for evaluating quality of life related to facial melasma. Methods: Cross-sectional study performed in 2 institutions (public and private) from Brazil. Two focus groups were carried out: 5 board-certified dermatologists and 10 melasma patients, indicating the dimensions and significant units of melasma QoL. The preliminary questionnaire with 49 itens was applied to 154 facial melasma patients. Item reduction was performed by Rasch analysis. Parallel evaluations of clinical (MASI), demographic, and QoL aspects (MELASQoL, DLQI) were performed. The dimensional structure was assessed by confirmatory factor analysis. Temporal stability was tested in a subgroup of 42 individuals within 7-14 days.

RESULTS: The mean (SD) age of the 154 interviewed subjects was 39 \pm 8 years, and $87 \%$ were females. The median (p25-p75) DLQI and MELASQoL were: 2 (1-6) and 30 (17-44). HRQ-Melasma consisted of 19 items distributed in 4 dimensions: Physical/ Appearance, Social/Professional, Psychological, and Treatment. Cronbach's alpha for HRQ-Melasma was 0.96, and >0.74 for each dimension. There was high correlation between HRQ-Melasma and DLQI and MELASQoL (rho=0.80 and 0.83), but modest with MASI (rho=0.35). Dimensional structure of HRQ-Melasma was stated by confirmatory factor analysis coefficients. Test-retest analysis disclosed an intraclass correlation coefficient of $0.91(\mathrm{p}<0.01)$.

STUDY LIMITATIONS: Single-center study.

CONCLUSIONS: A specific instrument to evaluate QoL in melasma with multidimensional characteristics was developed and validated, with appropriate psychometric performance.
\end{abstract}

Keywords: Melanosis; Psychometrics; Quality of life

\section{INTRODUCTION}

Melasma is a common chronic hypermelanosis characterized by symmetrical hyperchromic macules on photo-exposed skin, mainly the face. It occurs most frequently in childbearing-age women. Despite treatment, lesions tend to recur. ${ }^{1,2}$

Dermatoses can influence self-image and have the potential to trigger processes which affect self-esteem, promoting feelings of anxiety, unhappiness, or even depressive disorders. Although asymptomatic, melasma affects visible areas and has an important impact on quality of life (QoL).-6
The World Health Organization defines QoL as "individuals' perception of their position in life in the context of the culture and value systems in which they live and in relation to their goals, expectations, standards, and concerns". ${ }^{7}$ Meanwhile, health-related quality of life, which is a broad general concept that can vary significantly among different populations and cultures, is being used as an outcome in clinical trials. ${ }^{8}$

In 2003, the only specific instrument for evaluating melasma-related QoL was developed and validated: MELASQoL $(\mathrm{Me}-$ lasma Quality of Life Scale). The authors based it on SKINDEX-16 (7

Received 04 December 2016

Accepted 19 March 2017.

* Work conducted at the Department of Dermatology and Radiotherapy, Faculdade de Medicina, Universidade Estadual Paulista (FMB-Unesp), Botucatu (SP), Brazil.

Financial support: None.

Conflict of interest: None.

Department of Nursing, Faculdade de Medicina de Botucatu - Universidade Estadual Paulista (FMB-Unesp), Botucatu (SP), Brazil. Department of Dermatology, Faculdade de Medicina de Botucatu - Universidade Estadual Paulista (FMB-Unesp), Botucatu (SP), Brazil.

MAILING ADDRESS:

Hélio Amante Miot

E-mail: heliomiot@fmb.unesp.br

(C)2018 by Anais Brasileiros de Dermatologia 
items) and a questionnaire on changes in skin color (3 items). ${ }^{9} \mathrm{ME}$ LASQoL has been adapted and validated in different countries and used in various clinical trials. ${ }^{10-18}$

Criticisms have been raised about the construction process and application of MELASQoL, including: difficulties in the semantic interpretation of items, having been validated only in women, no prior qualitative analysis of perception about the disease, low representation of the dimension of feelings and selfesteem, lack of psychometric studies in relation to scalability, and temporal stability. ${ }^{19}$ These arguments indicate a need for developing new tools for evaluating QoL in melasma.

In this study we developed and validated a multidimensional instrument for evaluating QoL related to facial melasma in Brazil.

\section{METHODS}

This was a cross-sectional study performed at the School of Medicine of Unesp (Botucatu-SP), Brazil, from April 2014 to July 2015. The research project was approved by the Institutional Review Board of the institution (case review no. 476.666 / CAAE 24564413.3.0000.5411)

Patients were recruited from 2 institutions: FMB-Unesp Dermatology Outpatient Clinic (public) and Clínica Laura Buratini (private), in Botucatu, SP, Brazil.

Participation in the study included: 1) board-certified dermatologists and 2) patients with facial melasma over 18 years of age and from both genders, without other facial dyschromia.

\section{Focus Groups}

The first focus group consisted of 5board-certified dermatologists responding to the guided question: "In which aspects does melasma upset the life of patients?" This group oriented the main dimensions affected by melasma.

The second focus group consisted of 10 melasma patients recruited from the 2 institutions, responding to the guided question: "In your opinion, how does melasma affect your life?" within each dimension identified by the first focus group. These patients were selected on the basis of suitable intellectual and educational level for the discussion. This group provided information for item elaboration.

Both focus groups followed methodological steps: building a script of issues, formulation of representativeness criteria, and data collection on different individual perceptions.

The answers were recorded and analyzed according to Bardin content analysis, based on a preliminary definition of the dimensions affected by melasma (first focus groups). ${ }^{20}$

\section{Content Analysis}

The narratives were analyzed by following the steps of content analysis, in 3 phases. Pre-analysis: the organizational stage of the material and systematization of ideas; exploration of material: consisted of the data categorization operation in the transformation of raw data in order to achieve a core understanding of the text. This stage included cropping (selection of units of meaning) and data categorization. The last step was processing and interpretation of results.
The dermatologists' narratives were transcribed, and the instrument's dimensions emerged from these.

Patient narratives were transcribed and summarized to identify significant units, resulting in the preliminary composition of items for each dimension of the instrument.

\section{Semantic Adaptation and Content Validation}

The preliminary questionnaire, defined with 49 items in 7 dimensions, was analyzed by 5 specialists for item suitability (face validation) and semantics, and was also submitted to 10 patients for semantic and cultural adjustments to the items.

\section{Data Collection}

The preliminary questionnaire was applied to 154 facial melasma patients. Parallel evaluations were performed of clinical aspects (MASI - Melasma Area Severity Index), visual analogue scale for self-perception of inconvenience with 5 levels (developed for this study), and demographic and quality of life aspects: MELASQoL-PB, DLQI-BRA.,11,21-23

A convenience sample was used, with patients included after giving informed consent to participate in the study.

\section{Item Reduction}

The performance of items within each dimension was analyzed according to Item Response theory: polytomous Rasch model for ordinal data (Samejima graded model). ${ }^{24-26}$

Questionnaire reduction was accomplished according to the contribution of information from each item within each dimension, with low-informativity items being excluded. ${ }^{27,28}$

\section{Questionnaire Validation}

Validation of the reduced questionnaire (HRQ-Melasma) was performed by evaluating the internal consistency and correlation with other quality of life instruments (concurrent validity).

Dimensional Evaluation

The dimensional structure of HRQ-Melasma was tested by confirmatory factor analysis. Adjustment of the multidimensional model was performed through the following tests: chi-square by degrees of freedom ratio (CMIN/DF), adjusted goodness-of-fit index (AGFI), comparative fit index (CFI), and root mean square error of approximation (RMSEA). ${ }^{29,30}$

\section{Temporal Stability}

Test-retest stability of the final construct (HRQ-Melasma) and MELASQoL-BP in a subgroup of 42 individuals was analyzed 7-14 days after the interviews.

\section{Statistical Analysis}

Categorical variables were represented by their absolute values and percentage frequencies. Quantitative data were represented by means and standard deviations or medians and quartiles (p25-p75) if normality was not observed with the Kolmogorov-Smirnov test (Lilliefors). ${ }^{31}$

Correlation between HRQ-Melasma, MELASQoL-PB, DLQI-BRA, MASI, and visual scale of inconvenience scores were evaluated by Spearman's rank correlation coefficient (rho). ${ }^{31}$ 
Analysis of the internal consistency of the scale and dimensions was performed by Cronbach's alpha coefficient. ${ }^{32}$

Test-retest stability was evaluated by the intraclass correlation coefficient (ICC) for complete agreement. ${ }^{33}$

Scaling of HRQ-Melasma scores was based on the projection of DLQI categories ${ }^{22}$ using the cubic regression technique.

Data were tabulated in MS Excel 2010 spreadsheets and analyzed by IBM SPSS 22, eirt-1.3, and AMOS 10 software packages. ${ }^{34,35}$ Significance was set at $\mathrm{p}<0.05$.

Sample size was based on a pre-test interview of 100 individuals, performing an estimate of more than 10 cases per item within each dimension. ${ }^{36}$

\section{RESULTS}

Of the 154 individuals interviewed, 87 (57\%) were recruited from the outpatient clinic of a public university hospital and 67 (43\%) from a private clinic. The main clinical and demographic data are shown in table 1 . There was a predominance of females, and disease onset during childbearing age.

TABLE 1: Clinical, demographic, and quality of life data in patients with facial melasma

\begin{tabular}{|c|c|c|}
\hline Variables & & N (\%) \\
\hline $\mathrm{N}$ & & 154 \\
\hline Age (years)* & & $39(8)$ \\
\hline \multirow[t]{2}{*}{ Sex } & Female & $134(87)$ \\
\hline & Male & $20(13)$ \\
\hline \multirow[t]{3}{*}{ Marital status } & Single & $42(27)$ \\
\hline & Married/Stable union & $93(60)$ \\
\hline & Widow(ed) & $19(12)$ \\
\hline \multirow[t]{3}{*}{ Schooling } & Elementary & $28(18)$ \\
\hline & Secondary & $50(33)$ \\
\hline & University & $76(49)$ \\
\hline \multirow{4}{*}{$\begin{array}{l}\text { Monthly family } \\
\text { income }\end{array}$} & $<$ BRL 1,000.00 & $20(13)$ \\
\hline & BRL 1,100-3,000.00 & $51(33)$ \\
\hline & BRL 3,000-5,000.00 & $36(23)$ \\
\hline & $>$ BRL 5,000.00 & $47(31)$ \\
\hline $\begin{array}{l}\text { Age at onset of } \\
\text { melasma (years)* }\end{array}$ & & $27(8)$ \\
\hline Duration (years) ${ }^{* *}$ & & $10(6-16)$ \\
\hline MASI** $^{* *}$ & & $8(5-15)$ \\
\hline \multirow[t]{5}{*}{ Visual scale } & 1 - Not bothered & $14(9)$ \\
\hline & 2 - Slightly bothered & $25(16)$ \\
\hline & 3 - Moderately bothered & $43(28)$ \\
\hline & 4 - Very bothered & $34(22)$ \\
\hline & 5 - Extremely bothered & $38(25)$ \\
\hline DLQI-BRA** & & $2(1-6)$ \\
\hline MELASQoL-PB** & & $30(17-44)$ \\
\hline HRQ- MELASMA ** & & $31(15-52)$ \\
\hline
\end{tabular}

* Mean (standard deviation); **Median (p25-p75)
The first focus group (dermatologists) initially indicated 7dimensions. The second focus group (patients) led to the elaboration of 65 items which were later grouped into 49 items within 4 dimensions.

The test questionnaire was revised after a semantic review by patients and specialists, as well as validation of content, clarity, objectivity, appropriateness of terms, and ease of understanding, by specialists (data not shown). The test questionnaire with 49 items was then applied to 154 melasma patients.

The item reduction process within each dimension was based on the function of information expressed by each item according to Rasch analysis. The reduced questionnaire (HRQ-Melasma) resulted in 19 items (Chart 1) distributed in 4 dimensions (Physical/ Appearance, Social/Professional, Psychological, and Treatment).

High correlation was seen between test questionnaire scores and HRQ-Melasma (rho $=0.98 ; \mathrm{p}<0.01$ ).

Internal consistency (Cronbach's alpha) for HRQ-Melasma was 0.96, and as follows for the 4 dimensions: Physical/Appearance (0.88), Social/Professional (0.92), Psychological (0.94), and Treatment (0.74). There was high correlation between total and dimension scores (Table 2). Item-item correlations are shown in table 3.

Correlations between HRQ-Melasma and clinimetric or quality of life scores are shown in table 4 . There was only modest correlation between MELASQoL-PB and HRQ-Melasma and MASI. However, there was strong correlation between HRQ-Melasma and DLQI-BRA and MELASQoL-PB.

HRQ-Melasma allows a score ranging from zero to 76 . When compared to DLQI-BRA categories, projection of the scores permits their scaling thus: $<15$ (not affected); 16-35 (slightly affected); 36-50 (moderately affected); 51-65 (very affected); >65 (extremely affected). ${ }^{22}$

The dimensional structure of HRQ-Melasma, evaluated by confirmatory factor analysis, was based on the performance of the following indicators: chi-square by degrees of freedom ratio $(\mathrm{CMIN} / \mathrm{DF})=1.77(\mathrm{p}<0.01)$, adjusted goodness-of-fit index $(\mathrm{AGFI})$ $=0.84$, comparative fit index $(\mathrm{CFI})=0.96$; and root mean square error of approximation $($ RMSEA $)=0.06$. Performance of the indicators showed adequate fit to the latent dimensional structure: AGFI $\geq 0.9$; $\mathrm{CFI} \geq 0.9$; RMSEA $\leq 0.8$; and $\mathrm{CMIN} / \mathrm{DF}<5.23,24$

A retest of HRQ-Melasma was performed in 42 individuals with a mean interval of $9.5 \pm 2.6$ days. High temporal stability was demonstrated by intraclass correlation coefficient of the 2 measurements: $0.91(\mathrm{p}<0.01)$.

HRQ-QoL was completed by the subjects in less than 10 minutes.

\section{DISCUSSION}

A new multidimensional structured questionnaire was developed and validated to evaluate QoL in patients with facial melasma, following the classical steps of psychometry. ${ }^{37}$ The focus groups revealed different aspects of daily life in which the condition affects QoL.

The study sample was representative not only of Brazilian melasma patients as a whole (mainly childbearing-age women ${ }^{38,39}$ ), but also for development of the psychometric instrument, since it evaluated individuals with heterogeneous socioeconomic levels 
and age, gender, and clinical extent of the disease.

HRQ-Melasma was constructed by reducing 49 items to 19 , distributed in 4 broad dimensions which allowed the comprehension of the phenomenon in different domains of impact on QoL. The instrument displayed good internal consistency, as well as in its dimensions, and the item-reducing process did not introduce psychometric bias (rho > 0.95). The idealized dimensional structure was post-ratified by confirmatory factor analysis.

The Physical/Appearance dimension consisted of items that reflected aspects of the disease concerning aesthetic impact, pronounced aging, and differences in appearance relative to a group.

The Social/Professional dimension consisted of items that reflected the impact of the disease in relation to professional competitiveness, limitations in socializing, leisure, and building personal relations.

Feelings such as disappointment, embarrassment, sadness, depression, other people's perceptions of oneself, and harm to self-image and personal acceptance caused by the disease com-

CHART 1: Version of HRQ-Melasma in Brazilian Portuguese

\section{HRQ-Melasma}

The aim of this questionnaire is to measure how much the patches on your skin affected your life IN THE LAST 30 DAYS. Please mark the best answer to each question with an " $X$ ".

In the last 30 days how did you feel because of your patches?

PA1-How often did you feel that the patches made you look less beautiful (or handsome)?
( )0.Never/Does not apply
( )1.Rarely
( )2.Sometimes
()3.Often
( )4.Always

PA2-How often, because of the patches, did you feel you look older than you really are?
( )0.Never/ Does not apply
( )1.Rarely
()2.Sometimes
()3.Often
( )4.always

PA3-How often, because of the patches, did you feel different from other people?
( )0.Never/Does not apply
( )1.Rarely
( )2.Sometimes
()3.Often
( )4. Always

SP4-How often did the presence of the patches interfere in your activities or work?
( ) 0.Never/ Does not apply
()1.Rarely
()2.Sometimes
()3.Often
()4.Always

SP5- Because of your patches, how often did you feel uncomfortable meeting new people?
( ) 0.Never/ Does not apply
()1.Rarely
()2.Sometimes
()3.Often
()4.Always

SP6-How often did you feel bothered participating in daytime commitments?
( ) 0.Never/ Does not apply
()1.Rarely
()2.Sometimes

( )3.Often

( )4.Always

SP7-How often did the patches interfere in your seeking new job opportunities?
( )0.Never/ Does not apply
( )1.Rarely
( ) 2.Sometimes

( )3.Often

( )4.Always

SP8-How often did the patches limit your social activities, such as commitments, meetings, or interpersonal relations?
( )0.Never/ Does not apply
( )1.Rarely
( )2.Sometimes
( )3.Often
( )4. Always

PSY9-How often did you feel discouraged because your patches were a chronic, incurable problem?
( )0.Never/ Does not apply
( )1.Rarely
( )2. Sometimes
()3.Often
( )4.Always

PSY10-How often did you feel bothered by comments or questions by other people about your patches?
( ) 0. Never/ Does not apply
( )1.Rarely
( )2.Sometimes
( )3.Often
()4.Always

FA11-How often did you think your patch looked ugly?
( )0.Never/ Does not apply
()1.Rarely
( )2.Sometimes
( )3.Often
()4.Always

PSY12-How often did you feel ashamed of your patches?
( )0.Never/ Does not apply
()1.Rarely
()2.Sometimes
()3.Often
( )4.Always

PSY13-How often did you avoid or feel bad looking in the mirror because of the patches?
()0.Never/ Does not apply
()1.Rarely
()2.Sometimes
( )3.Often
( )4.Always

PSY14-How often did you feel bothered when other people stared at you and noticed the patches?
( ) 0.Never/ Does not apply
()1.Rarely
()2.Sometimes
()3.Often
( )4.Always

PSY15-How often did you feel sad or depressed because of the patches?
( ) 0.Never/ Does not apply
()1.Rarely
( )2.Sometimes
( )3.Often
( )4.Always

PSY16-How often did you have trouble accepting the patches?
( )0.Never/ Does not apply
( )1.Rarely
( )2.Sometimes
()3.Often
()4.Always

RX17-How often did you find that the treatment products or sunscreens were not adapted to your kind of skin?
( )0.Never/ Does not apply
( )1.Rarely
( )2.Sometimes
()3.Often
()4.Always

RX18-In the last 30 days, how often did you feel bothered by the side effects from the treatment? For example: redness. RX19-How often did you feel bothered because the patches got darker in spite of the treatment?

( ) 0.Never/ Does not apply

( )1.Rarely

( )2.Sometimes

()3.Often

( )4.Always 


TABLE 2: Spearman's correlation (rho) for total score and di-
mensions of HRQ-Melasma

PA- Physical/Appearance SP- Social/Professional PSY- Psychological RX- Treatment
TABLE 4: Spearman's correlation (rho) for clinical, self-image, and quality of life instruments applied in the study

\begin{tabular}{|c|c|c|c|c|}
\hline & 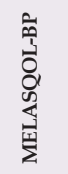 & $\begin{array}{l}\overleftrightarrow{心} \\
\stackrel{0}{0} \\
\stackrel{0}{0}\end{array}$ & 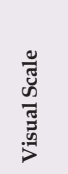 & 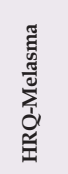 \\
\hline MASI & 0.35 & 0.27 & 0.39 & 0.35 \\
\hline MELASQoL-BP & & 0.73 & 0.72 & 0.83 \\
\hline DLQI-BRA & & & 0.67 & 0.80 \\
\hline Visual Scale & & & & 0.74 \\
\hline
\end{tabular}

All p-values were $<0.01$

\begin{tabular}{|c|c|c|c|c|c|c|c|c|c|c|c|c|c|c|c|c|c|c|c|}
\hline & $\begin{array}{c}\text { PA } \\
2\end{array}$ & $\begin{array}{c}\text { PA } \\
3\end{array}$ & $\begin{array}{c}\text { PA } \\
18\end{array}$ & $\begin{array}{c}\text { SP } \\
6\end{array}$ & $\begin{array}{c}\text { SP } \\
7\end{array}$ & $\begin{array}{l}\text { SP } \\
10\end{array}$ & $\begin{array}{l}\text { SP } \\
11\end{array}$ & $\begin{array}{l}\text { SP } \\
12\end{array}$ & $\begin{array}{c}\text { PSY } \\
15\end{array}$ & $\begin{array}{c}\text { PSY } \\
16\end{array}$ & $\begin{array}{c}\text { PSY } \\
21\end{array}$ & $\begin{array}{c}\text { PSY } \\
23\end{array}$ & $\begin{array}{c}\text { PSY } \\
25\end{array}$ & $\begin{array}{c}\text { PSY } \\
28\end{array}$ & $\begin{array}{c}\text { PSY } \\
30\end{array}$ & $\begin{array}{c}\mathrm{RX} \\
39\end{array}$ & $\begin{array}{c}\mathrm{RX} \\
45\end{array}$ & $\begin{array}{l}\mathrm{RX} \\
46\end{array}$ & $\begin{array}{c}\text { HRQ- } \\
\text { Melasma }\end{array}$ \\
\hline PA1 & 0.69 & 0.66 & 0.71 & 0.42 & 0.51 & 0.47 & 0.46 & 0.42 & 0.70 & 0.61 & 0.73 & 0.65 & 0.63 & 0.53 & 0.60 & 0.33 & 0.35 & 0.52 & 0.80 \\
\hline PA2 & & 0.69 & 0.64 & 0.48 & 0.55 & 0.48 & 0.50 & 0.50 & 0.59 & 0.61 & 0.66 & 0.59 & 0.64 & 0.61 & 0.59 & 0.30 & 0.39 & 0.49 & 0.78 \\
\hline PA3 & & & 0.56 & 0.59 & 0.59 & 0.52 & 0.51 & 0.53 & 0.60 & 0.62 & 0.66 & 0.63 & 0.67 & 0.62 & 0.58 & 0.25 & 0.29 & 0.46 & 0.78 \\
\hline PA18 & & & & 0.45 & 0.49 & 0.46 & 0.39 & 0.41 & 0.72 & 0.58 & 0.70 & 0.61 & 0.63 & 0.53 & 0.59 & 0.33 & 0.36 & 0.58 & 0.78 \\
\hline SP6 & & & & & 0.65 & 0.70 & 0.65 & 0.73 & 0.50 & 0.54 & 0.57 & 0.55 & 0.54 & 0.61 & 0.49 & 0.23 & 0.25 & 0.40 & 0.69 \\
\hline SP7 & & & & & & 0.64 & 0.61 & 0.64 & 0.48 & 0.56 & 0.63 & 0.63 & 0.56 & 0.57 & 0.44 & 0.29 & 0.24 & 0.42 & 0.71 \\
\hline SP10 & & & & & & & 0.64 & 0.72 & 0.51 & 0.53 & 0.59 & 0.63 & 0.53 & 0.59 & 0.56 & 0.27 & 0.25 & 0.45 & 0.72 \\
\hline SP11 & & & & & & & & 0.66 & 0.47 & 0.53 & 0.52 & 0.53 & 0.49 & 0.63 & 0.46 & 0.21 & 0.25 & 0.33 & 0.65 \\
\hline SP12 & & & & & & & & & 0.50 & 0.49 & 0.55 & 0.55 & 0.55 & 0.58 & 0.46 & 0.26 & 0.28 & 0.45 & 0.69 \\
\hline PSY15 & & & & & & & & & & 0.68 & 0.77 & 0.66 & 0.70 & 0.62 & 0.64 & 0.32 & 0.42 & 0.71 & 0.84 \\
\hline PSY16 & & & & & & & & & & & 0.73 & 0.66 & 0.80 & 0.61 & 0.61 & 0.36 & 0.52 & 0.59 & 0.83 \\
\hline PSY21 & & & & & & & & & & & & 0.75 & 0.80 & 0.71 & 0.70 & 0.26 & 0.41 & 0.60 & 0.88 \\
\hline PSY23 & & & & & & & & & & & & & 0.71 & 0.66 & 0.63 & 0.33 & 0.37 & 0.50 & 0.83 \\
\hline PSY25 & & & & & & & & & & & & & & 0.66 & 0.65 & 0.31 & 0.44 & 0.59 & 0.84 \\
\hline PSY28 & & & & & & & & & & & & & & & 0.63 & 0.24 & 0.34 & 0.47 & 0.78 \\
\hline PSY30 & & & & & & & & & & & & & & & & 0.37 & 0.40 & 0.50 & 0.76 \\
\hline RX39 & & & & & & & & & & & & & & & & & 0.45 & 0.41 & 0.45 \\
\hline RX45 & & & & & & & & & & & & & & & & & & 0.57 & 0.53 \\
\hline RX46 & & & & & & & & & & & & & & & & & & & 0.72 \\
\hline
\end{tabular}

PA- Physical/Appearance SP- Social/Professional PSY- Psychological RX- Treatment

prised the Psychological dimension, with the largest number (7) of items in HRQ-Melasma.

The Treatment dimension included only 3 items and showed low informativity according to Rasch analysis. However, it was an independent dimension that explored important aspects of the disease: intervention tolerability and lesion recurrence despite treatment.

HRQ-Melasma also correlated highly with the visual scale of inconvenience, DLQI-BRA, and MELASQoL-PB. The weak correlation of HRQ-Melasma and MELASQoL-PB with MASI showed that the impact of melasma transcends the Physical dimension. ${ }^{40}$
Likewise, test-retest stability was high, altogether lowing its use in clinical practice and research.

The study's main limitation was its single-center design. The psychometric and structural properties of HRQ-Melasma should be explored in other cultural and linguistic settings with analytical tools adjusted to the measures' statistical characteristics in order to identify the construct's strengths and weaknesses for investigating quality of life in melasma.

\section{CONCLUSIONS}

We developed a specific multidimensional instrument to assess QoL in melasma, with suitable psychometric performance. $\square$ 


\section{REFERENCES}

1. Handel AC, Miot LD, Miot HA. Melasma: a clinical and epidemiological review. An Bras Dermatol. 2014;89:771-82.

2. Miot LD, Miot HA, Polettini J, Silva MG, Marques ME. Morphologic changes and the expression of alpha-melanocyte stimulating hormone and melanocortin-1 receptor in melasma lesions: a comparative study. Am J Dermatopathol. 2010;32:676-82

3. Taborda M-LV, Weber MB, Freitas ES. Assessment of the prevalence of psychological distress in patients with psychocutaneous disorder dermatoses. An Bras Dermatol 2005;80:351-4.

4. Ikino JK, Nunes DH, Silva VP, Fröde TS, Sens MM. Melasma and assessment of the quality of life in Brazilian women. An Bras Dermatol. 2015;90:196-200.

5. Purim KS, Avelar MF. Photoprotection, melasma and quality of life in pregnant women. Rev Bras Ginecol Obstet. 2012 ;34:228-34.

6. Shuster S, Fisher GH, Harris E, Binnell D. The effect of skin disease on self image. Br J Dermatol. 1978;99:18-9.

7. The World Health Organization Quality of Life assessment (WHOQOL): position paper from the World Health Organization. Soc Sci Med. 1995;41:1403-9.

8. Halioua B, Beumont MG, Lunel F. Quality of life in dermatology. Int J Dermatol. 2000;39:801-6.

9. Balkrishnan R, McMichael AJ, Camacho FT, Saltzberg F, Housman TS, Grummer $\mathrm{S}$, et al. Development and validation of a health-related quality of life instrument for women with melasma. Br J Dermatol. 2003;149:572-7.

10. Misery L, Schmitt AM, Boussetta S, Rahhali N, Taieb C. Melasma: measure of the impact on quality of life using the French version of MELASQOL after crosscultural adaptation. Acta Derm Venereol. 2010:90:331-2.

11. Cestari TF, Hexsel D, Viegas ML, Azulay L, Hassun K, Almeida AR, et al. Validation of a melasma quality of life questionnaire for Brazilian Portuguese language: the MelasQoL-BP study and improvement of QoL of melasma patients after triple combination therapy. Br J Dermatol. $2006: 156: 13-20$.

12. González Gómez LJ. Validación de la escala de calidad de vida MELASQoL, en un grupo de pacientes colombianas con melasma [tese]. Bogotá (D.C.): Univerisdad del Rosario; 2010; 59p.

13. Dogramaci AC, Havlucu DY, Inandi T, Balkrishnan R. Validation of a melasma quality of life questionnaire for the Turkish language: the MelasQoL-TR study. J Dermatolog Treat. 2009;20:95-9.

14. Abou-Taleb DA, Youssef EM, Ibrahim AK, Moubasher AE. Reliability and validity of the Arabic version of the Melasma Quality of Life questionnaire:(MELASQDL-A) study. Clin Dermatol 2014; 2:121-7.

15. Song M, Mun JH, Ko HC, Kim BS, Kim MB. Korean red ginseng powder in the treatment of melasma: an uncontrolled observational study. J Ginseng Res. 2011;35:170-5

16. Hwang SW, Oh DJ, Lee D, Kim JW, Park SW. Clinical efficacy of $25 \%$ L-ascorbic acid (C'ensil) in the treatment of melasma. J Cutan Med Surg. 2009; 13:74-81.

17. Dominguez AR, Balkrishnan R, Ellzey AR, Pandya AG. Melasma in Latina patients: cross-cultural adaptation and validation of a quality-of-life questionnaire in Spanish language. J Am Acad Dermatol. 2006;55:59-66.

18. Alvin G, Catambay N, Vergara A, Jamora MJ. A comparative study of the safety and efficacy of $75 \%$ mulberry (Morus alba) extract oil versus placebo as a topical treatment for melasma: a randomized, single-blind, placebo-controlled trial. J Drugs Dermatol. 2011;10:1025-31.
19. Maranzatto CF, Miot HA, Miot LD, Meneguin S. Psychometric analysis and dimensional structure of the Brazilian version of melasma quality of life scale (MELASQoL-BP). An Bras Dermatol. 2016:91:422-8.

20. Bardin L. Análise de conteúdo. Lisboa: Ediçōes 70; 2009.

21. Pandya AG, Hynan LS, Bhore R, Riley FC, Guevara IL, Grimes P, et al. Reliability assessment and validation of the Melasma Area and Severity Index (MASI) and a new modified MASI scoring method. J Am Acad Dermatol. 2011;64:78-83, 83.e1-2.

22. Finlay AY, Khan GK. Dermatology Life Quality Index (DLQI)--a simple practical measure for routine clinical use. Clin Exp Dermatol. 1994:19:210-6.

23. Silvares MR, Fortes MR, Miot HA. Quality of life in chronic urticaria: a survey at a public university outpatient clinic, Botucatu (Brazil). Rev Assoc Med Bras (1992). 2011;57:577-82.

24. Linacre JM. Many-facet Rasch measurement. Chicago (IL): Mesa Press; 1998.

25. Chachamovich E. Teoria da resposta ao item: aplicação do modelo Rasch em desenvolvimento e validação de instrumentos em saúde mental [tese]. Porto Alegre (RS): Universidade Federal do Rio Grande do Sul; 2007.

26. Smith AB, Rush R, Fallowfield LJ, Velikova G. Sharpe M. Rasch fit statistics and sample size considerations for polytomous data. BMC Med Res Methodol. 2008;8:33.

27. Erhart M, Hagquist C, Auquier P, Rajmil L, Power M, Ravens-Sieberer U, et al. A comparison of Rasch item-fit and Cronbach's alpha item reduction analysis for the development of a Quality of Life scale for children and adolescents. Child Care Health Dev. 2010; 36:473-84.

28. Prieto L, Alonso J, Lamarca R. Classical Test Theory versus Rasch analysis for quality of life questionnaire reduction. Health Qual Life Outcomes. 2003;1:27.

29. Muraki E. Fitting a polytomous item response model to Likert-type data. App Psy Meas 1990;14:59-71.

30. Steger MF. An illustration of issues in factor extraction and identification of dimensionality in psychological assessment data. J Pers Assess. 2006;86:263-72.

31. Norman GR, Streiner DL. Biostatistics: the bare essentials. 4th ed. Shelton (CT): PMPH-USA; 2014

32. Bland JM, Altman DG. Cronbach's alpha. BMJ. 1997;314:572.

33. Miot HA. Agreement analysis in clinical and experimental trials. J Vasc Bras. 2016;15:89-92

34. IBM SPSS 22.0 Statistics for Windows. Armonk (NY): IBM Corp; 2013.

35. Miot HA. Assessing normality of data in clinical and experimental trials. J Vasc Bras. 2017;16: 88-91.

36. Miot HA. Sample size in clinical and experimental trials. J Vasc Bras. 2011;10:275-8.

37. Streiner DL, Norman GR, Cairney J. Health measurement scales: a practical guide to their development and use: Oxford: Oxford University Press; 2014.

38. Tamega Ade A, Miot LD, Bonfietti C, Gige TC, Marques ME, Miot HA.. Clinical patterns and epidemiological characteristics of facial melasma in Brazilian women. J Eur Acad Dermatol Venereol. 2013;27:151-6.

39. Hexsel D, Lacerda DA, Cavalcante AS, Machado Filho CA, Kalil CL, Ayres EL, et al. Epidemiology of melasma in Brazilian patients: a multicenter study. Int $J$ Dermatol. 2014:53:440-4.

40. Freitag FM, Cestari TF, Leopoldo LR, Paludo P, Boza JC.. Effect of melasma on quality of life in a sample of women living in southern Brazil. J Eur Acad Dermato Venereol. 2008:22:655-62.

$\begin{array}{ll}\text { Camila Fernandes Pollo } & \text { (D) ORCID 0000-0003-0264-5841 } \\ \text { Luciane Donida Bartoli Miot } & \text { (D) ORCID 0000-0002-2388-7842 }\end{array}$

$\begin{array}{ll}\text { Silmara Meneguin } & \text { (D) ORCID 0000-0003-3853-5134 } \\ \text { Hélio Amante Miot } & \text { (D) ORCID 0000-0002-2596-9294 }\end{array}$

How to cite this article: Pollo CF, Miot LDB, Meneguin S, Miot HA. Development and validation of a multidimensional questionnaire for evaluating quality of life in melasma (HRQ-melasma). An Bras Dermatol. 2018;93(3):391-6. 